\title{
STRATEGI GURU DALAM MENERAPKAN PEMBELAJARAN HOTS MENGGUNAKAN MODEL PROBLEM BASED LEARNING
}

\author{
Ummi Inayati ${ }^{1}$ \\ ienayaazzaheen@gmail.com
}

STAI Attanwir Bojonegoro

\begin{abstract}
Education in Indonesia is currently undergoing a significant improvement. Particularly in welcoming the revolution era of the 4.0, which is required learning model with high levelthingking or commonly known as HOTS (Higher Order Thinking Skills). In addition to thinking critically and creatively, problem solving is also included as thinking characters in high-level skills. Solving problems in the learning process trains learners to resolve problems in real life. In fact, not all teachers can simply apply it. Therefore, HOTS learning using the problem based learning model requires strategy for more effective and efficient study. The research methods used in this study are qualitative descriptive, data collection techniques used by conducting observations, interviews in-depth and document research. The key informant in the study was a class III teacher at SDN Lengkong Bojonegoro, while the informant was a class III student. The data obtained is analyzed using interactive models (data collection, data presentation, reduction, drawing conclusions). The results of this study show that the teacher's strategy in implementing HOTS learning is a good problem based learning model. Visible from the indicators used through deep interview to the key informant and the informant. The obstacles experienced are differences in understanding, characteristics, learning style of students when learning, teachers are required to always be creative and innovative packing learning and the limitations of school facilities and infrastructure.
\end{abstract}

Keywords: Strategy, HOTS learning, Problem Based Learning

\begin{abstract}
Abstrak
Saat ini pendidikan di Indonesia secara terus menerus mengalami perbaikan secara signifikan. Menyambut era revolusi 4.0 khususnya, diperlukan adanya pembelajaran yang dikemas dengan keterampilan berfikir tingkat tinggi atau biasa dikenal dengan istilah HOTS (Higher Order Thinking Skills). Selain berfikir kritis dan kreatif, pemecahan masalah termasuk karakter keterampilan berfikir tingkat tinggi. Pemecahan masalah dalam proses pembelajaran melatih peserta didik untuk menyelesaikan masalah secara nyata. Pada kenyataanya tidak semua guru bisa dengan mudah menerapkan pembelajaran tersebut. Oleh karena itu pembelajaran HOTS menggunakan model problem based learning memerlukan strategi agar pembelajaran bisa berjalan dengan efektif dan efesien. Metode penelitian yang digunakan yaitu kualitatif deskriptif, teknik pengumpulan data yang digunakan dengan cara melakukan observasi, wawancara secara mendalam dan penelitian dokumen. Informan kunci pada penelitian ini adalah guru kelas III SDN Lengkong Bojonegoro, sedangkan informan adalah peserta didik kelas III. Data yang
\end{abstract}

\footnotetext{
${ }^{1}$ Dosen Pendidikan Guru Madrasah Ibtidaiyah, STAI Attanwir Bojonegoro
} 


\section{Ummi Inayati}

diperoleh dianalisis menggunakan model interaktif (pengumpulan data, penyajian data, reduksi, menarik kesimpulan). Hasil penelitian ini menunjukkan bahwa strategi guru dalam menerapkan pembelajaran HOTS menggunakan model problem based learning cukup baik. Terlihat dari indikator-indikator yang digunakan melalui wawancata mendalam kepada informan kunci dan para informan. Adapun kendala yang dialami yaitu perbedaan pemahaman, karakteristik, gaya belajar peserta didik ketika belajar, guru dituntut untuk selalu kreatif dan inovatif mengemas pembelajaran dan adanya keterbatasan sarana dan prasarana sekolah.

Kata kunci: Strategi, Pembelajaran HOTS, Problem Based Learning

\section{Pendahuluan}

Seiring dengan menggaungnya seruan menyongsong era 4.0 diharapkan adanya perubahan paradigma dalam pelaksanaan pembelajaran di sekolah. Langkah yang perlu disiapkan dalam menyongsong era 4.0 salah satunya yaitu melalui pembelajaran dengan menumbuhkan berfikir tingkat tinggi atau lebih dikenal dengan pembelajaran HOTS (High Order Thinking Skill). pembelajaran ini menumbuhkan adanya proses berfikir secara kritis, kreatif, kecakapan pemecahan masalah dan lain-lain. ${ }^{2}$ Aspek yang ditekankan pada dimensi keterampilan yaitu agar peserta didik mempunyai keterampilan berfikir dan bertindak. Misalnya peserta didik kreatif, produktif, mandiri dan komunikatif.

Model problem based learning (PBL) adalah model pembelajaran yang menitik beratkan pada kegiatan belajar peserta didik yang berorientasi pada masalah sebagai bahan belajar. PBL mempunyai tujuan untuk meningkatkan kemampuan dalam menerapkan konsep-konsep pada permasalahan baru atau nyata, pengintegrasian konsep HOTS, keinginan dalam belajar, mengarahkan diri sendiri dan keterampilan. ${ }^{3}$ Oleh karenanya guru sebagai ujung tombak pembelajaran di kelas diharapkan mampu memahami dengan benar serta mampu menyiapkan pembelajaran HOTS menggunakan model problem based learning agar peserta didik mempunyai keterampilan dan kecakapan sesuai dengan apa yang diinginkan guna mempersiapkan generasi yang siap menghadapi peluang dan tantangan era 4.0.

Menurut pendapat Resnik, HOTS adalah kompleksitas berfikir yang diawali dari menguraikan materi, mengambil kesimpulan, membangun representasi, menganalisa serta mengkonstruk hubungan dengan mengaitkan aktivitas mental yang paling dasar. Keterampilan-

2 Ai Ratna Nurhayati, Asep Kurnia Jayadinata, Atep Sujana. Penerapan Inkuiri Terbimbing dalam Meningkatkan Keterampilan Berpikir Kritis Peserta didik Kelas V Pada Materi Daur Air. Program studi PGSD UPI Kampus Sumedang.

3 Amidi M. Zuhair Zahid. 2016. Membangun Kemampuan Berpikir Kreatif Matematis dengan Model Pembelajaran Berbasis Masallah Berbantuan e-Learning. FMIPA Universitas Negeri Semarang.

28| Jurnal Auladuna 
keterampilan seperti keterampilan bertahan hidup sangat dibutuhkan untuk menjawab tuntutan zaman, dunia kerja, kewarganegaraan. Pada abad 21, ada tujuh keterampilan yang mendasari yaitu kemampuan berfikir kritis dan pemecahan masalah, kolaborasi dan kepemimpinan, ketangkasan dan kemampuan beradaptasi, inisiatif dan berjiwa entrepreneur, keterampilan berkomunikasi efektif baik lisan maupun tulisan mampu mengakses dan menganalisis informasi atau data, dan memiliki rasa ingin tahu yang tinggi. ${ }^{4}$ Ciri pembelajaran berbasis masalah adalah adanya permasalahan yang diajukan kepada siswa pada awal pembelajaran dan harus dicari pemecahannya. Aktivitas pemecahan masalah ini akan menstimulasi dan mengembangkan keterampilan berpikir dan bernalar. ${ }^{5}$

Hasil wawancara kepada guru kelas III menyatakan bahwa pada prakteknya pembelajaran HOTS tidak mudah dilakukan oleh guru. Perlu adanya persiapan khusus selain penguasaan materi, metode, media, dan evaluasi pembelajaran. Persiapan tersebut jarang dilakukan oleh guru sebelum mengajar. Rata-rata guru hanya berbekal metode penugasan dan ceramah. Media pembelajaran yang diterapkan juga seadanya, belum ada pembaharuan. Guru merasa ada yang kurang meskipun ada guru yang sudah mulai menerapkan pembelajaran sesuai prosedural. Pada pembelajaran berbasis masalah ini guru merasa kesulitan menentukan tema atau masalah yang tepat untuk dijadikan bahan pembelajaran yang dikemas dalam pembelajaran HOTS ini. Hal yang harus benar-benar dikuasai dan dipersiapkan adalah strategi pembelajaran. Implementasi model pembelajaran model PBL merupakan peluang bagi guru untuk menerapkan kegiatan pembelajaran pada level HOTS.

Berdasarkan uraian permasalahan tersebut mendorong peneliti melakukan penelitian dengan tujuan untuk mengetahui bagaimana strategi guru dalam menerapkan pembelajaran HOTS menggunakan model problem based learning meliputi bagaimana perencanaan guru, proses pelaksanaan, evaluasi pembelajaran, dan kendala yang dialami guru.

\section{Pembahasan}

Pada proses pembelajaran di tahap perencanaan guru menyiapkan segala sesuatu terkait pembelajaran. Misalnya memahami karakter pembelajaran HOTS dan model PBL, menyiapkan

\footnotetext{
${ }^{4}$ Zubaidah. 2017. Berfikir Kritis: Kemampuan Berfikir Tingkat Tinggi yang dapat dikembangkan melalui Pembelajaran Sains. FMIPA Universitas Negeri Malang

${ }^{5} \mathrm{~J}$, Alim. 2008. Pembelajaran Matematika dengan Pendekatan Pemecahan Masalab untuk. Meningkatkan Keterampilan Berpikir Kritis dan Kreatif Siswa Sekolah Dasar. Tesis pada Prodi Pendidikan Dasar FPS UPI Bandung. 


\section{Ummi Inayati}

Rencana Pelaksanaan Pembelajaran (RPP), media pembelajaran dan evaluasi pembelajaran yang sesuai dengan model PBL.

Berdasarkan wawancara guru menyatakan bahwa karakteristik pada pembelajaran HOTS berbeda dengan pembelajaran pada umumnya, pembelajaran HOTS melatih siswa berfikir secara kritis, kreatif, komunikatif, mampu menyelesaikan masalah, aktif dan melibatkan keterampilan serta kecakapan lain yang komprehensif. Jadi strategi pertama adalah perlunya pemahaman guru mengenai karakter pembelajaran HOTS sebelum guru tersebut mengimplementasikan di kelas. Hal ini senada dengan pernyataan Hosnan bahwa ada tujuh karakterisik pembelajaran HOTS meliputi: 1) Aktivitas kegiatan belajar mengajar berpusat pada peserta didik (Student Centered). 2) Pembelajaran mengacu pada ranah kreativitas peserta didik. 3) Pembelajaran bersifat menarik, bermakna dan menyenangkan. 4) Pembelajaran di desain mengembangkan berbagai kemampuan atau keterampilan yang berisi nilai dan makna. 5) Learning by doing (belajar sambil melakukan). Peserta didik dituntut aktif berbuat. 6) Berorientasi pada penggalian informasi, penemuan pengetahuan dan penciptaan karya atau fakta. 7) Pembelajaran menggunakan pendekatan kontektual, yaitu mengajak siswa belajar melalui kondisi yang nyata sesuai konteks sebenarnya. Persiapan fisik dan mental juga harus dipersiapkan. ${ }^{6}$

SDN Lengkong melakukan persiapan dengan matang sebelum proses pembelajaran dimulai. Strategi guru adalah guru mendalami karakter pembelajaran HOTS dan PBL. Guru mempunyai strategi khusus dalam pembelajaran tersebut, diantaranya guru menyiapkan media proyektor dengan memutarkan video tentang cara menghemat energi. Guru memanfaatkan sarana dan prasarana yang ada untuk memaksimalkan proses pembelajaran. Kemudain, guru menyiapkan RPP. Adapun RPP yang digunakan sama dengan RPP yang biasa digunakan yaitu RPP K13, yang membedakan hanya di bagian inti karena harus ada penjelasan lebih tentang model PBL serta menyiapkan media yang sesuai. Berdasarkan RPP yang dibuat oleh guru, RPP dirancang sesuai dengan pembelajaran HOTS melalui model pembelajaran berbasis masalah.diantaranya guru sudah menentukan tujuan pembelajaran yang ingin dicapai, media pembelajaran yang akan digunakan, langkah-langkah yang rinci menggunakan pembelajaran berbasis masalah serta bentuk penilaian yang akan dilaksanakan. RPP tersebut dirancang

6 M, Hosnan. 2014. Pendekatan Saintifik dan Kontekstual dalam Pembelajaran Abad 21 Kunci Sukses Implementasi Kurikulum 2013. Bogor: Ghalia Indonesia.

30| Jurnal Auladuna 
dengan baik dengan mempertimbangkan alokasi waktu, karakter siswa dan sarana dan prasarana.

Perencanaan lain yang dilakukan guru adalah dengan mempersiapkan fisik, mental yang matang. Karena dalam pembelajaran ini memerlukan energi yang cukup baik fisik dan mental agar pembelajaran bisa berjalan dengan baik. Guru juga menyiapkan hadiah atau penghargaan bagi peserta didik sebagai bentuk motivasi agar peserta didik semangat ketika belajar. Uzer Usman menyatakan bahwa guru harus memperhatikan beberapa hal dalam membuat rencana pembelajaran yang sesuai dengan RPP dalam menentukan keberhasilan proses belajar mengajar.

Pada pembelajaran inti guru menjelaskan dan memperlihatkan video tentang cara menghemat energi kemudian peserta didik dibentuk kelompok dan diberikan tugas untuk mengetes sejauh mana peserta didik memahami materi yang telah sampaikan. Guru melaksanakan sesuai dengan langkah-langkah model PBL. Pertama guru menyajikan masalah berupa cara menghemat BBM. Pembelajaran peserta didik yang berorientasi pada masalah menumbuhkan berfikir kritis terhadap penyelesaian masalah tersebut. ${ }^{7}$ Langkah kedua yaitu membagi siswa kedalam beberapa kelompok. Hal ini menumbuhkan sikap adanya kerjasama yang baik antar peserta didik serta melatih kecakapan social peserta didik. Selanjutnya, langkah ketiga yang dilakukan guru adalah guru membimbing dengan ekstra dalam mengarahkan penyelidikan terhadap masalah yang dihadapi. Pada tahap ini guru sangat berperan karena peserta didik memerlukan arahan ketika mengalami kesulitan dalam memecahkan masalah. Langkah kelima yaitu mengembangkan dan menyajikan hasil diskusi tentang cara menghemat BBM. Setelah peserta didik menyelesaikan tugasnya, peserta didik diminta untuk memaparkan hasilnya secara bergantian antar kelompok. Langkah terakhir yaitu membuat kesimpulan dengan menganalisis dan mengevaluasi proses diskusi. Selanjutnya peseta didik diajak untuk menyimpulkan bersama-sama pembelajaran yang sudah dilakukan. Langkah ini sesuai dengan pendapat Arend tentang model PBL yaitu pembelajaran peserta didik berorientasi pada masalah, mengorganisasikan peserta didik untuk belajar, guru membimbing atau mengarahkan penyelidikan individu maupun kelompok, mengembangkan dan menyajikan hasil karya,

7 Ni Nyoman Ely Triyuni, Ni Nyoman Kusmariyatni, I Gede Margunayasa. Pengembangan Perangkat Pembelajaran Inkuiri Terbimbing Berbasisi Aktivitas Higher Order Thingking (HOT) pada Tema 8 Subtemma 1 Kelas V SD. Journal of Education Technology. Vol. 3 (1). Universitas Pendidikan Ganesha, 2019. 


\section{Ummi Inayati}

Menganalisis dan mengevaluasi proses pemecahan masalah. ${ }^{8}$ Langkah-langkah tersebut juga sependapat dengan pendapat Ibrahim mengenai langkah pembelajaran berbasis masalah adalah (1) tahap orientasi siswa pada masalah, (2) tahap mengorganisasikan siswa untuk belajar, (3) tahap membimbing penyelidikan individu maupun kelompok, (4) tahap mengembangkan dan menyajikan hasil karya, (5) tahap menganalisis dan mengevaluasi proses pemecahan masalah. ${ }^{9}$

Pada kegiatan evaluasi atau penilaian ini guru melakukannya pada kegiatan penutup. Guru menggunakan evaluasi khusus untuk menilai peserta didik pada pembelajaran model PBL ini. Peserta didik dinilai dari hasil kerja perkelompok yang sudah dikerjakan, keikutsertaan dalam mengerjakan tugas berdasarkan indikator penilaian yang telah dipersiapkan oleh guru sebelumnya. Adapun tindak lanjut yang dilakukan guru adalah memberi penjelasan kembali dengan detail dan mendalam tentang materi yang sudah dijelaskan serta peserta didik diminta untuk remidi atau pengayaan. ${ }^{10}$ Selain itu guru juga memberikan motivasi kepada peserta didik agar selalu meningkatkan belajarnya. Penilaian hasil belajar lebih menitikberatkan pada kemampuan berpikir tingkat tinggi (Higher Order Thinking Skills/HOTS). ${ }^{11}$ Melalui penilaian berbasis pada soal-soal HOTS, keterampilan berpikir kritis (creative thinking and doing), kreativitas (creativity) dan rasa percaya diri (learning self reliance), akan dibangun melalui kegiatan latihan menyelesaikan berbagai permasalahan nyata dalam kehidupan sehari-hari (problem-solving). Penilaian yang berkualitas akan dapat meningkatkan mutu pendidikan. Dengan membiasakan melatih siswa untuk menjawab soal-soal HOTS, maka diharapkan siswa dapat berpikir secara kritis dan kreatif. ${ }^{12}$ Soal-soal yang diberikan bukanlah soal yang sulit, berbelit-belit dan panjang redaksinya akan tetapi disusun secara sistematis, proporsional untuk mengukur Indikator Ketercapaian Kompetensi (IKK) secara efektif serta mewakili kedalaman materi, sehingga peserta didik mendapat stimulus untuk menjawab soal dengan baik. ${ }^{13}$

\footnotetext{
${ }^{8}$ Winny Liliawati. 2011. Pembekalan keterampilan berfikir kreatif siswa SMA melalui pembelajaran fisika berbasis masalah. Jurusan pendidikan fisika FPMIPA Universitas Pendidikan Indonesia.

9 Ibrahim, M. dan Nur, M. 2005. Pengajaran Berdasarkan Masalah (Edisi 2). Surabaya: Unesa - University Press.

10 Anderson, L.W. \& Krathwohl, D.R. 2010. Kerangka Landasan untuk Pembelajaran, Pengajaran dan Assessment. Yogyakarta: Pustaka Pelajar

11 Kemendikbud, 2017. Modul Penyusunan Higher Order Thinking Skill (HOTS). Jakarta: Direktort Jenderal Pendidikan Dasar dan Menengah Departeman Pendidikan dan Kebudayaan.

12 Nurdinah Hanifah. 2019. Pengembangan Instrumen Penilaian Higher Order Thinking Skill (HOTS) di sekolah dasar. Program studi PGSD. Universitas Pendidikan Indonesia, Kampus Sumedang

13 Ariyana, Yoki. 2018. Buku Pegangan Pembelajaran Berorientasi pada Keterampilan Berfikir Tingkat Tinggi (Program Peningkatan Kompetensi Pembelajaran Berbasis Zonasi). Jakarta: Direktorat Jenderal Guru dan Tenaga Kependidikan Kementrian Pendidikan dan Kebudayan

32| Jurnal Auladuna
} 
Penerapan pembelajaran HOTS menggunakan model PBL ini memiliki beberapa kendala, diantaranya peserta didik memiliki kemampuan pemahaman yang berbeda, sehingga yang lamban belajar kurang tanggap dalam menjawab pertanyaan yang diberikan guru. Peserta didik memiliki karakter, gaya belajar yang berbeda ketika belajar. Tidak semua peseta didik bisa diajak untuk bekerjasama menyelesaikan masalah yang diberikan. Guru dituntut untuk selalu kreatif dan inovatif mengemas pembelajaran. Factor lain karena keterbatasan sarana dan prasarana yang ada di sekolah.

\section{Penutup}

Strategi yang dilakukan guru dalam menerapkan pembelajaran HOTS menggunakan PBL ini ada tiga, pertama pada kegiatan perencanaan yaitu guru menyiapkan fisik dan mental, menyiapkan RPP yang berbasis HOTS menggunakan model PBL, menyiapkan media serta evaluasi yang sesuai. Kedua pada pembelajaran inti yaitu guru melakukan pembelajaran menggunakan langkah-langkah PBL. Dimulai dari menyajikan masalah berupa cara menghemat BBM, mengorganisasikan belajar, mengarahkan secara konstruktif bagaimana cara menghemat BBM, menyajikan hasil diskusi dan menyimpulkan. Ketiga, menutup pembelajaran dengan membuat kesimpulan bersama-sama dan mengevaluasi dengan pertanyaan berbasis HOTS meliputi aspek sikap, pengetahuan dan keterampilan. Adapun kendala yang dialami dalah tidak semua siswa cakap dalam memecahkan masalah karena perbedaan pemahaman, karakteristik, gaya belajar dan lain-lain. Kendala yang lain adalah guru dituntut untuk selalu kreatif dan inovatif dalam mengemas pembelajaran dan keterbatasan sarana dan prasarana yang ada di sekolah.

\section{Referensi}

\begin{tabular}{|c|l|l|}
\hline 1 & $\begin{array}{l}\text { Nurhayati, A.R., Jayadinata, A.K., Sujana, A. Penerapan Inkuiri Terbimbing dalam } \\
\text { Meningkatkan Keterampilan Berpikir Kritis Peserta didik Kelas V Pada Materi Daur Air. } \\
\text { Sumedang: PGSD UPI. }\end{array}$ \\
\hline 2 & $\begin{array}{l}\text { Zahid, A.M.Z. 2016. Membangun Kemampuan Berpikir Kreatif Matematis dengan Model } \\
\text { Pembelajaran Berbasis Masallah Berbantuan e-Learning. Semarang: FMIPA Universitas } \\
\text { Negeri Semarang. }\end{array}$ \\
\hline 3 & $\begin{array}{l}\text { Zubaidah, S. 2017. Berfikir Kritis: Kemampuan Berfikir Tingkat Tinggi yang dapat } \\
\text { dikembangkan melalui Pembelajaran Sains. Malang: FMIPA Universitas Negeri Malang. }\end{array}$ \\
\hline
\end{tabular}




\begin{tabular}{|c|l|}
\hline 4 & $\begin{array}{l}\text { Alim, J. 2008. Pembelajaran Matematika dengan Pendekatan Pemecahan Masalah untuk } \\
\text { Meningkatkan Keterampilan Berpikir Kritis dan Kreatif Siswa Sekolah Dasar. Tesis. Bandung: } \\
\text { FPS UPI. }\end{array}$ \\
\hline 5 & $\begin{array}{l}\text { Hosnan, M. 2014. Pendekatan Saintifik dan Kontekstual dalam Pembelajaran Abad 21 Kunci } \\
\text { Sukses Implementasi Kurikulum 2013. Bogor: Ghalia Indonesia. }\end{array}$ \\
\hline 6 & $\begin{array}{l}\text { Triyuni, N.N.E., Kusmariyatni, N.N., Margunayasa, I.G. 2019. Pengembangan Perangkat } \\
\text { Pembelajaran Inkuiri Terbimbing Berbasisi Aktivitas Higher Order Thingking (HOT) pada Tema } \\
\text { 8 Subtemma 1 Kelas V SD. Journal of Education Technology. Vol. 3 (1). Bali: Universitas } \\
\text { Pendidikan Ganesha. }\end{array}$ \\
\hline 7 & $\begin{array}{l}\text { Liliawati, W. 2011. Pembekalan Keterampilan Berfikir Kreatif Siswa SMA Melalui Pembelajaran } \\
\text { Fisika Berbasis Masalah. Bandung: FPMIPA Universitas Pendidikan Indonesia. }\end{array}$ \\
\hline 8 & $\begin{array}{l}\text { Ibrahim, M. dan Nur, M. 2005. Pengajaran Berdasarkan Masalah. Ed. Ke-2. Surabaya: } \\
\text { Unesa-University Press. }\end{array}$ \\
\hline 9 & $\begin{array}{l}\text { Anderson, L.W. dan Krathwohl, D.R. 2010. Kerangka Landasan untuk. Pembelajaran, } \\
\text { Pengajaran dan Assessment. Yogyakarta: Pustaka Pelajar. }\end{array}$ \\
\hline 10 & $\begin{array}{l}\text { Kemendikbud. 2017. Modul Penyusunan Higher Order Thinking Skill (HOTS). Jakarta: } \\
\text { Direktorat Jenderal Pendidikan Dasar dan Menengah Departeman Pendidikan dan } \\
\text { Kebudayaan. }\end{array}$ \\
\hline 11 & $\begin{array}{l}\text { Hanifah, Nurdinah. 2019. Pengembangan Instrumen Penilaian Higher Order Thinking Skill } \\
\text { (HOTS) di Sekolah Dasar. Sumedang: Universitas Pendidikan Indonesia. }\end{array}$ \\
\hline 12 & $\begin{array}{l}\text { Ariyana, Y. 2018. Buku Pegangan Pembelajaran Berorientasi pada Keterampilan Berfikir Tingkat } \\
\text { Tinggi Program Peningkatan Kompetensi Pembelajaran Berbasis Zonasi). Jakarta: Direktorat } \\
\text { Jenderal Guru dan Tenaga Kependidikan Kementrian Pendidikan dan Kebudayan. }\end{array}$ \\
\hline
\end{tabular}

34| Jurnal Auladuna 